Original Research Paper

\title{
Concentration of Carbon Monoxide in an Enclosed Parking Garage
}

\author{
${ }^{1}$ Nayef Z. Al-Mutairi, ${ }^{2}$ Talal Almutairi and ${ }^{2}$ Hamad B. Matar \\ ${ }^{1}$ Department of Civil Engineering, College of Engineering and Petroleum, Kuwait University, Kuwait \\ ${ }^{2}$ Department of Civil Engineering, College of Technological Studies (PAAET), Kuwait
}

\author{
Article history \\ Received: 08-04-2020 \\ Revised: 08-06-2020 \\ Accepted: 30-07-2020 \\ Corresponding Author: \\ Nayef Z. Al-Mutairi \\ Department of Civil \\ Engineering, College of \\ Engineering and Petroleum, \\ Kuwait University, Kuwait \\ Email: nayef.almutairiku.edu.kw
}

\begin{abstract}
The findings of this preliminary study could be indicative of all other Kuwait car parks. The extension of the enclosed car park facilities situated in the heavy building cellars will in the near future allow the results of this study to determine the predicted air quality standards and their associated issues for a first time. Further work is required, however, to establish more precisely the relation between the regular $\mathrm{CO}$ rates. In order to determine the exposure levels of those who operate on these included facilities, the long-life control of $\mathrm{CO}$ levels inside enclosed garages is important. In a follow up analysis, it is important to analyze and assess the connection between the $\mathrm{CO}$ rates and their health effects.
\end{abstract}

Keywords: Carbon Monoxide, Enclosed Garage, Health Impacts

\section{Introduction}

Air contamination has adverse impacts on environmental quality and above all human wellbeing. It is the subject of new policies and studies. Many cancers (such as lung cancer, leukemia, asthma) and early birth and death are linked to air pollutants (Dockery et al., 1994; Calderón-Garcidueñas et al., 2003; Wilhelm and Ritz, 2003). This was classified by the (IARC, 2012) as a category 1 human carcinogenic diesel extractor. Vermeulen et al. (2014) reported that $6 \%$ of lung cancer deaths are induced by industrial diesel use.

Multiple transport systems that contribute to environmental and workplace exposures produce significant quantities of air emissions from vehicles. Recent research shows that traffic is the main source of air pollution in Kuwait's urban areas, (Al-Mutairi and Koushki, 2009). It is reported that about 600 million citizens in 2002 were subjected in urban areas to high air pollutant rates (Cacciola et al., 2002) according to figures from the United Nations. While several studies cover air pollutants generated by vehicles, human exposure levels in microenvironments could and are not properly studied, give rise to further concerns. The parking garage is one of the most significant microenvironments in which car drivers and workers are vulnerable to harmful air emissions (Kim et al., 2007). Carbon monoxide (CO) is one of Car exhaust's main environmental pollutants.

There are several questions about running cars in underground garages. The more serious the build-up of
Caron Monoxide (CO) is because of its specific dangers. Another issue can require awareness of diesel engine fuel emissions or NOx. The air vents required to control $\mathrm{CO}$ at acceptable levels are usually often necessary to regulate the amount of other pollutants so that the diesel vehicles ratio does not surpass $20 \%$ (ASHRAE, 2007).

Emissions of carbon dioxide are released explicitly out of automotive exhausts or indirectly from fuel tanks into the soil in car parks (Höglund, 2004). Garage CO rates are primarily dictated by the amount of traffic and air supply (Chan and Chow, 2004; Koskela et al., 1991; Demir, 2015) are essential to the detection of ventilation (Chan and Chow, 2004). Because people will spend only short time in enclosed car parks, it is likely that the average $\mathrm{CO}$ level in insufficiently ventilated car parks would negatively affect staff and other garage users in particular (Wallace, 1983).

For parking garages there are no strict levels of appropriate $\mathrm{CO}$, since these restrictions vary across several guidelines from countries and agencies. Throughout the US, the American Governmental Industrial Hygienists (ACGIH) 'Association-suggests an intake $\mathrm{CO}$ level of $25 \mathrm{ppm}(29 \mathrm{mg} / \mathrm{m})$ for $8 \mathrm{~h}$. The National Institute for Health and Safety (NIOSH) proposes a maximum limit of $25 \mathrm{ppm}$ while Occupational Safety and Health Administration (OSHA) advises a maximum of $50 \mathrm{ppm}$ of $\mathrm{CO}$ for a worker to be exposed in an eight hour period. Average concentrations in Europe of 35 ppm (26 in Poland, 30 in Finland, 50 in UK) are typically maintained in car parks. Given the 
variances in the range of exposure of $35 \mathrm{ppm}$ for an $8 \mathrm{~h}$ span, US Society of ASHRAE (2007) indicates that driving in/out or parking is in order of minutes.

Data from three Kuwait National Public National Operational Authority (KEPA) air monitoring systems for seven years (1998-2004) have been examined by (Al-Mutairi and Koushki, 2009) and they noticed that concentration of several air contaminants like $\mathrm{CO}$ increased marginally over the study span, but was not above expectations. The literature review, however, indicates that $\mathrm{CO}$ rates in Kuwait have not been tested in the micro-environment. Contained car garages in public buildings and malls are becoming increasingly popular in Kuwait today because of population expansion and because of the harsh weather of Kuwait. This study addresses the reduction of this research gap.

In addition, traditional fuel-powered vehicles (i.e., gasoline and diesel) are producing contaminants by two basic processes: Combustion pollution and evaporative emissions. Pollutants from exhaust are commonly called "tail-tube" emissions and are the result of the vehicle's combustion of petrol. The amount of pollution of exhaust depends significantly on how the engine runs. Three types of service are usually used with lightduty vehicles: Cold start, hot start and heat stabilized. The first few minutes after starting the motor would be included in the Start phase. The time between shutdown and restart differentiates the cold from the hot beginning. When the engine runs after the start stage, the heat controlled state happens. Generally, $\mathrm{CO}, \mathrm{NOx}$ and VOC pollution levels in hot starts than cold starts are lower and vigorously stable.

Evaporative Emissions consist of hydrocarbons released from the fuel collection and delivery system. The evaporative emissions exist through several processes including hot-soak emissions (from carburetor or fuel injector when the engine is idle), diurnal emissions (due to temperature fluctuations over one day), running loses, resting losses, refueling losses and crankcase emissions. Several criteria influence motor vehicle emission levels of $\mathrm{CO}, \mathrm{NOx}$ and VOCs.

A new design approach is needed to determine the ventilation rate necessary for a wide range of enclosed parking garages. This design approach should be scalable to meet not only the different $\mathrm{CO}$ exposure limits established by the regulations but also the evolving pollution inventory from motor vehicles. Auto pollution levels have usually declined over the years due to stricter emission requirements for cars. In the future, this pattern will most likely continue as low or zero emission vehicles become more common.

It should be remembered, though, that all the laws examined in this study are focused on single chemicals and do not take into account the consequences of exposure to mixtures like fuel fumes. On the other side, the $\mathrm{CO}$ intake relies on $\mathrm{CO}$ content in the breathing environment. The amount of $\mathrm{CO}$ within a parking garage depends on several factors, such as vehicle type, ambient temperature and engine operating mode and is, thus, difficult to estimate. Well-controlled automobiles and good pedestrian traffic can, therefore, minimize the sensitivity to the respiratory zone $\mathrm{CO}$ to rates that are below those that occur in other areas of parking garages (Chow et al., 1996).

A research paper (Chow et al., 1996) has also addressed the field assessment of ventilation system performance in enclosed parking garages. The findings of the field test were introduced in seven US car parks of varying sizes to assess the ventilation criteria and rates of pollutants. The study contrasted the actual ventilation levels that were calculated using the gas trace technologies. The findings of the field analysis have been derived from the following conclusions:

- The included parking garage samples produce considerably lower rates of pollutants than even the lowest criteria (i.e., an average $\mathrm{CO}$ concentration of $25 \mathrm{ppm}$ per hour weighted) are needed

- The average ventilation thresholds for the checked parking garages typically fall well short of those suggested by Standard 62-1989 (i.e., 1.5 $\mathrm{cfm} / \mathrm{ft} 2$ or $7.5 \mathrm{~L} / \mathrm{s} \mathrm{m}^{2}$ )

- Once used, indoor air quality inside the study enclosed parking facilities was improved through demand regulated ventilation

- The direction of the intake and exhaust planes, the traffic patterns, numbers of moving cars and the duration of transport are important factors influencing the ventilation system's efficacy to retain acceptable levels of $\mathrm{CO}$ (or NOx) in enclosed parking lots. To order to evaluate airflow criteria for an enclosed car park, all construction manuals will take these considerations into consideration

In 1991, a group of researchers from the Department of Community Medicine of Kuwait University (9) performed a report on traffic air quality in Kuwait. The mean average NOx concentrations approached $50 \mathrm{ppb}$ at 90 percent of the locations and frequently hit a high of $500 \mathrm{ppb}$ at peak traffic hours. Around the same period, the regular average concentration of $\mathrm{CO}$ was above 8 ppm at or equivalent to $8 \%$ of the sites and $\mathrm{CO}$ rates were greater than $20 \mathrm{ppm}$ at three places. Throughout the week, regular discrepancies with the lowest rates of contaminants reported during the weekend were identified (9).

An investigation paper (10) examined a study into Carbon Monoxide from Riyadh Traffic. Carbon Monoxide $(\mathrm{CO})$ concentrations were calculated in three 
rapidly transferred arterials in Riyadh over a two-year duration (1985-1986). Maeasurements of rush hours at three places at each arterial study: One at the traffic core and another at two sidewalk limits. Measurements were proceeded. The normal delivery volume and combination were also calculated and weather data were collected for each arterial sample. CO concentrations were often above 100 ppm during the rush hours. The mean rates in both 1 and $8 \mathrm{~h}$ periods were significantly higher than Saudi Arabian Air Quality Standards (SAAQS). Over the two-year observation span, $\mathrm{CO}$ concentrations increased slightly. At approximately $50 \%$ of the measuring points, this rise was statistically significant $(\mathrm{a}=0,05$ level). Correlation analysis revealed that variables of amount of hourly traffic, wind speed and the ratio of road dimension show a high degree of linear contact with concentration distribution in Riyadh streets (10).

The aims of the analysis were: (1) To equate the reported $\mathrm{CO}$ rates to the prescribed $\mathrm{CO}$ rates in the correct Standards (2) to take into account the effect of $\mathrm{CO}$ measures from garage and consumer exposure levels; (3) to equate the $\mathrm{CO}$ incidence of enclosed garage at various select sites with an accessible car park. The findings of this analysis could be a valuable method in other garages with specific situations for solving possibly possible issues.

\section{Methodology}

In this study $\mathrm{CO}$ parameters was measured in specific points of the avenues parking garage and airport short parking garage. The study area description and methodology used to select measurement technique were presented in the next part.

\section{A. Site Description}

The Avenues is considered one of the largest enclose shopping mall in the Middle East and the largest in Kuwait (Fig. 1). In 2007, the first phase of the mall was open and today the fourth (last) phase will be open soon. It located at Al Rai Industrial district in estimated area of $340,260.45 \mathrm{~m}^{2}$. Two major highways, Fifth Ring Road to the south and Al Ghazali Highway to the east, are adjacent to the mall. The mall has more the 12000 parking spaces, which were in open space, building garage and three level basements (Fig. 2). Each basement level provides 3000 parking space. It has mechanical ventilation system. This study focus in three buildings garage located at north of the Avenues as shown in Fig. 3. Each building garage consists of two basements, which has mechanical ventilation system and six floors with natural ventilation. It has one access point to access the mall at each floor and one enters and exit for cars.

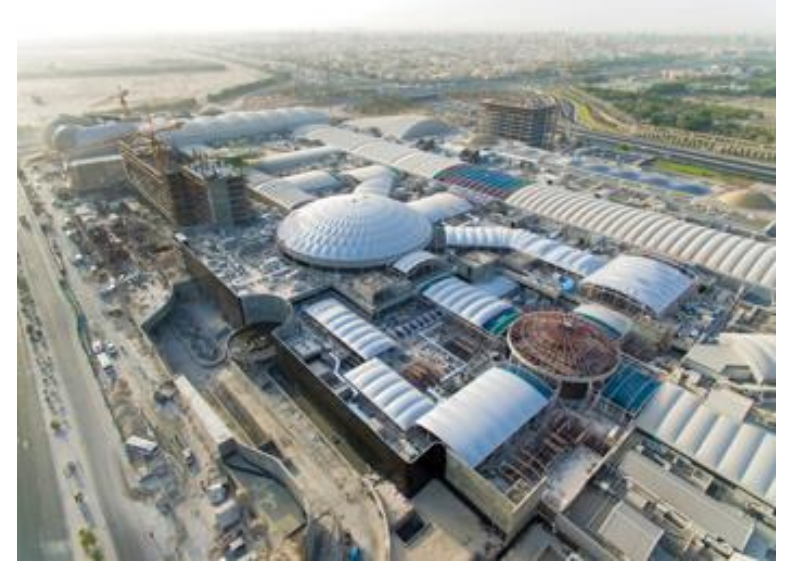

Fig. 1: The avenues mall

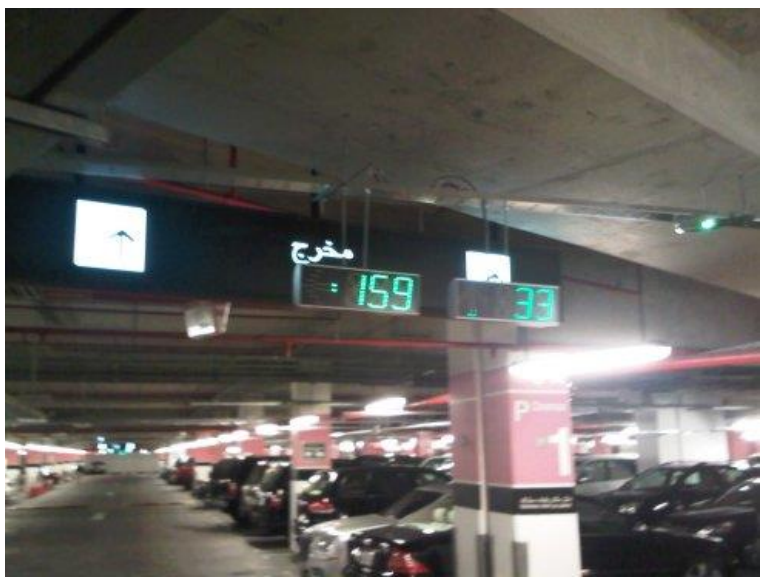

Fig. 2: The Avenues mall parking enclosed parking garage

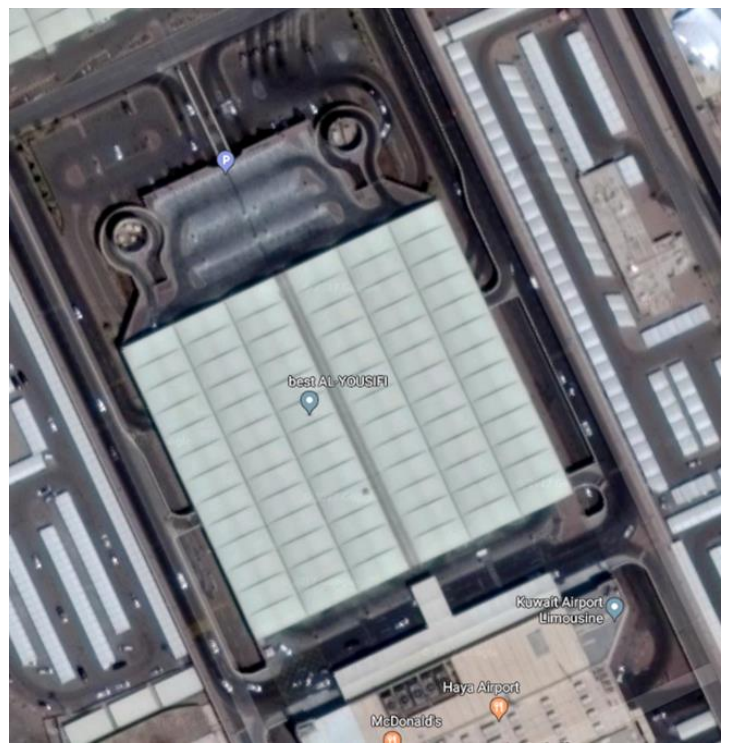

Fig. 3: Buildings garage under study located at north of the Avenues 


\section{B. CO Monitoring}

In this study, the HOBO Carbon Monoxide Loggers, by Onset Computer Corporation (Bourne, MA), devices were used to monitor $\mathrm{CO}$ in the range of $0.2-2000 \mathrm{ppm}$ with a resolution of $0.5 \mathrm{ppm}$. The $\mathrm{CO}$ monitoring is based on electrochemical sensor. The device has been used in several studies. The devices were calibrated before each monitoring period according to manufacturer specification. The logger was setup to record data in one minute integral.

The campaign was conducted in Kuwait in October 2017. It involved measurement CO levels at three buildings car park and short term parking at the Avenues Mall during weekdays and weekend. Several points were chosen for CO level measuring. At each corner of floor, car access point and pedestrian access point to each floor either to Mall. The $\mathrm{CO}$ devices were position 1 to $1.5 \mathrm{~m}$ from the floor level to be at breathing zone. The data represent $\mathrm{CO}$ level at the time of monitoring periods. The locations of monitoring sites were selected to represent car park occupant conditions. An electronic thermometer was used to record outdoor and indoor air temperatures. The ambient conditions were compare against data collected. Other data were collected, such as the car park occupancy, number of cars exiting and entering the parking and mean time walking from the car to entrance and vice versa.

\section{Results and Discussion}

An effort was also made to equate concentrations of $\mathrm{CO}$ in roads with those in the sample car parks. The average $\mathrm{CO}$ amount in $60 \%$ of the test garages was about $8 \mathrm{ppm}$, while $88 \%$ of the survey streets in Kuwait City had the same findings. There is no $\mathrm{CO}$ mean concentration of $>20 \mathrm{ppm}$ on any parking garage in Kuwait, while concentration in $\mathrm{CO}$ rates exceeded this amount in three sample streets. The key observations of the analysis are outlined in the following portion and observations are taken on these results.

The outcome of an indoor microenvironmental survey is described in this analysis of the parking garages under study. The investigation was significant because no previous research had been carried out in Kuwait's metropolitan environments regarding the assessment and interpretation of air pollution concentrations inside parking garages. Measurements of fields on the $\mathrm{CO}$ rates are recorded for a duration of nine months inside the parking garages under study at three positions on each parking floor replicated 8 times per floor. Only $\mathrm{CO}$ was present inside the test garages in the air when $\mathrm{NO}, \mathrm{NO}_{2}$ and $\mathrm{CH} 4$ in any of the research parking could not be identified.

In evening cycles the average $\mathrm{CO}$ rates were above the normal $8 \mathrm{~h}$ minimum $(9 \mathrm{ppm})$ in the winter time. The $\mathrm{CO}$ rates inside enclosed car parks may have a detrimental impact on the wellbeing of parking workers, such as headache. In the experimental test car park garages, the mean 1-hr level (35 ppm) concentration never surpassed over the entire hour. However, within the sample garages $\mathrm{CO}$ rates above $40(\mathrm{ppm})$ were reported over a short period of time (Fig. 4 to 7 ).

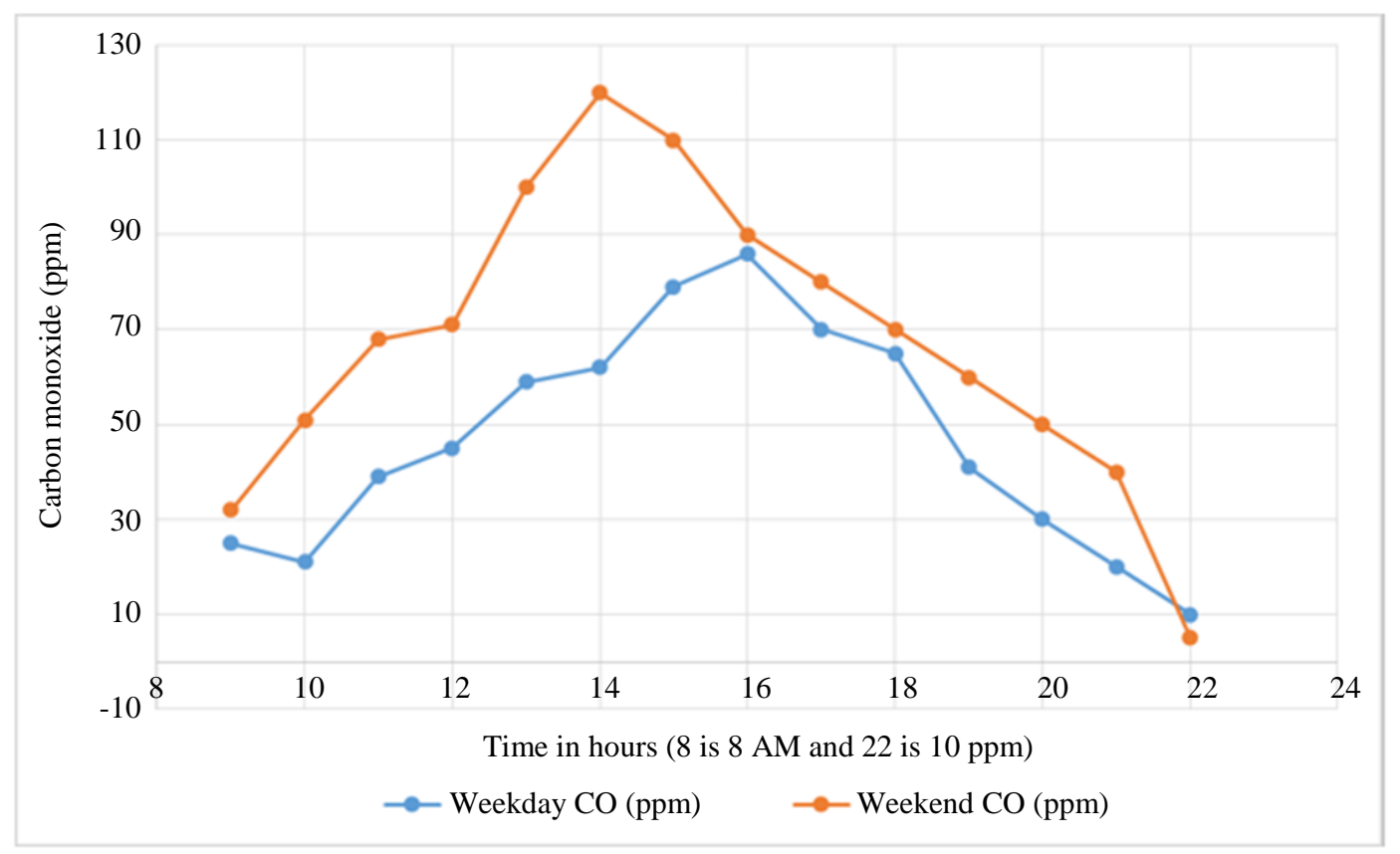

Fig. 4: CO concentration (ppm) averaged over $60 \mathrm{~min}$ in the Avenues enclosed Garage monitored during the Winter time 
The $\mathrm{CO}$ concentration trends showed that $\mathrm{CO}$ rates are based on parking garage size/capacity (number of stalls), temperature, moisture and daytime. The tests revealed a strong degree of maximum $\mathrm{CO}$ production at elevated levels, with a lower moisture content even over the night hours in broad sealed car parks. The CO rates do rely, of course, on the number of vehicles entering and exiting. The above relationships have been verified by the correlation coefficients of average $\mathrm{CO}$ levels with vehicle flow test factors, everyday temperature, humidity levels, garage size and daytime. Nonetheless, there have been few important associations between daytime and the overall amount of cars entering and exiting the car park. In the analysis of the relationship between the mean $\mathrm{CO}$ level and car flow at various station floors several pattern models have been also established. The exponential function was the best fit model form.

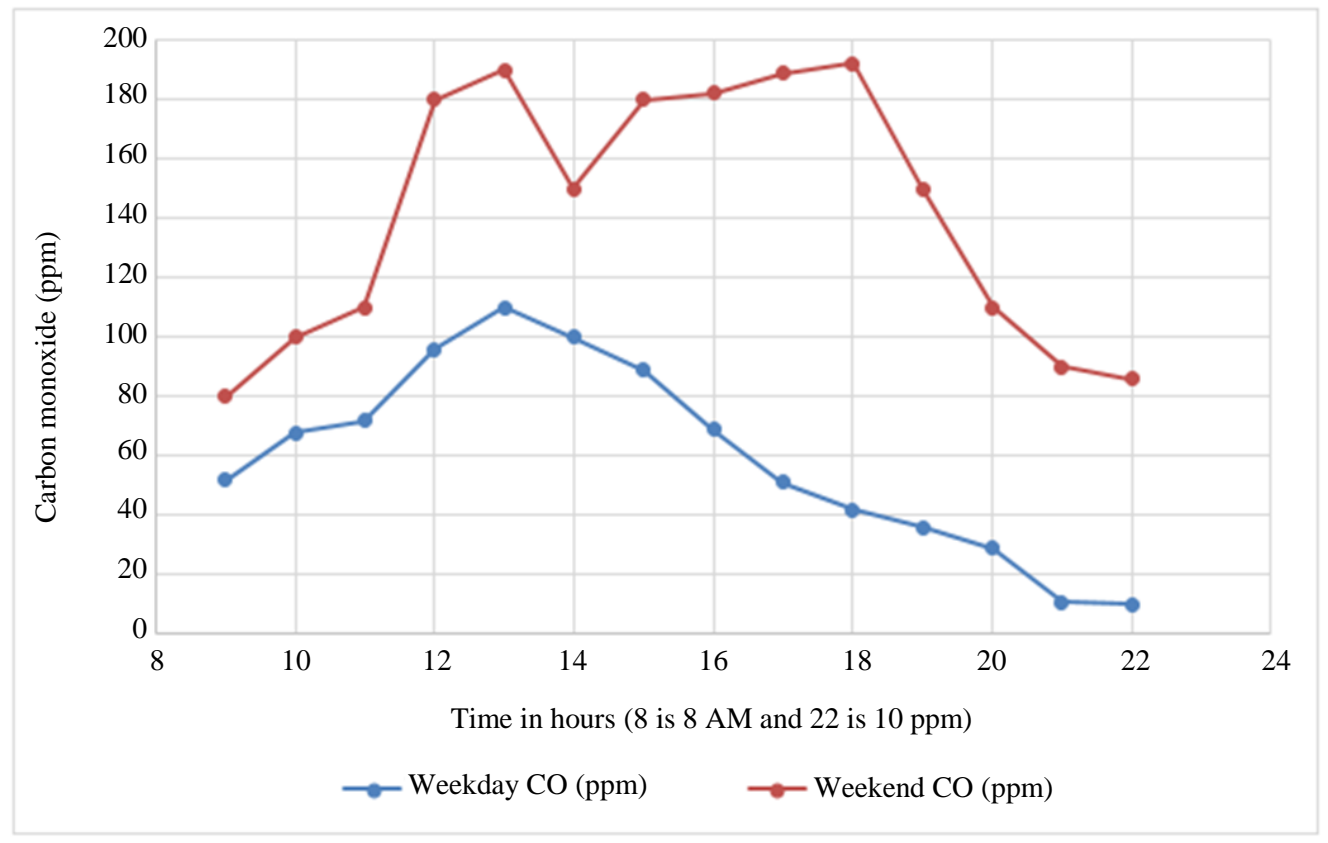

Fig. 5: CO concentration (ppm) averaged over $60 \mathrm{~min}$ in the Avenues enclosed Garage monitored during the Summer time

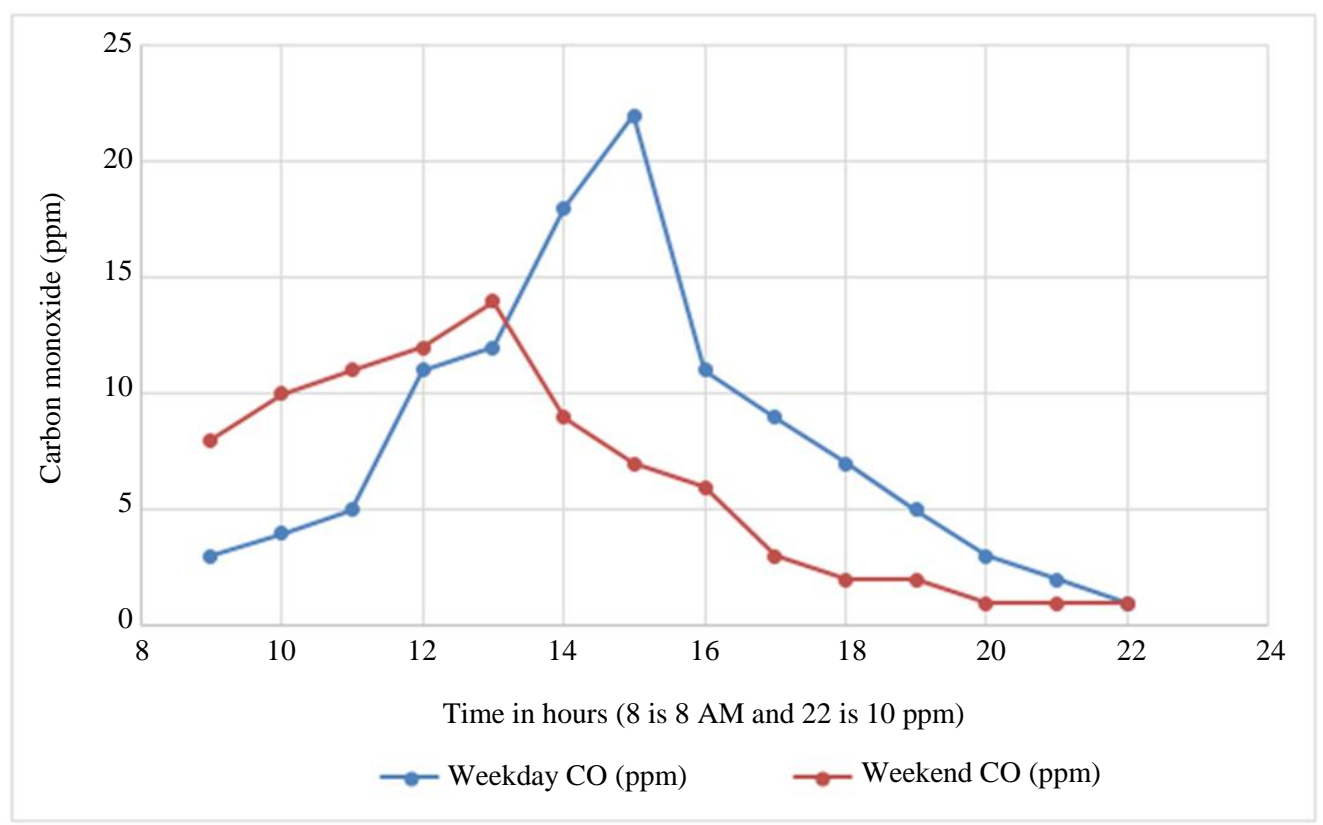

Fig. 6: CO concentration (ppm) averaged over $60 \mathrm{~min}$ in the Avenues open space Garage monitored during the Winter time 


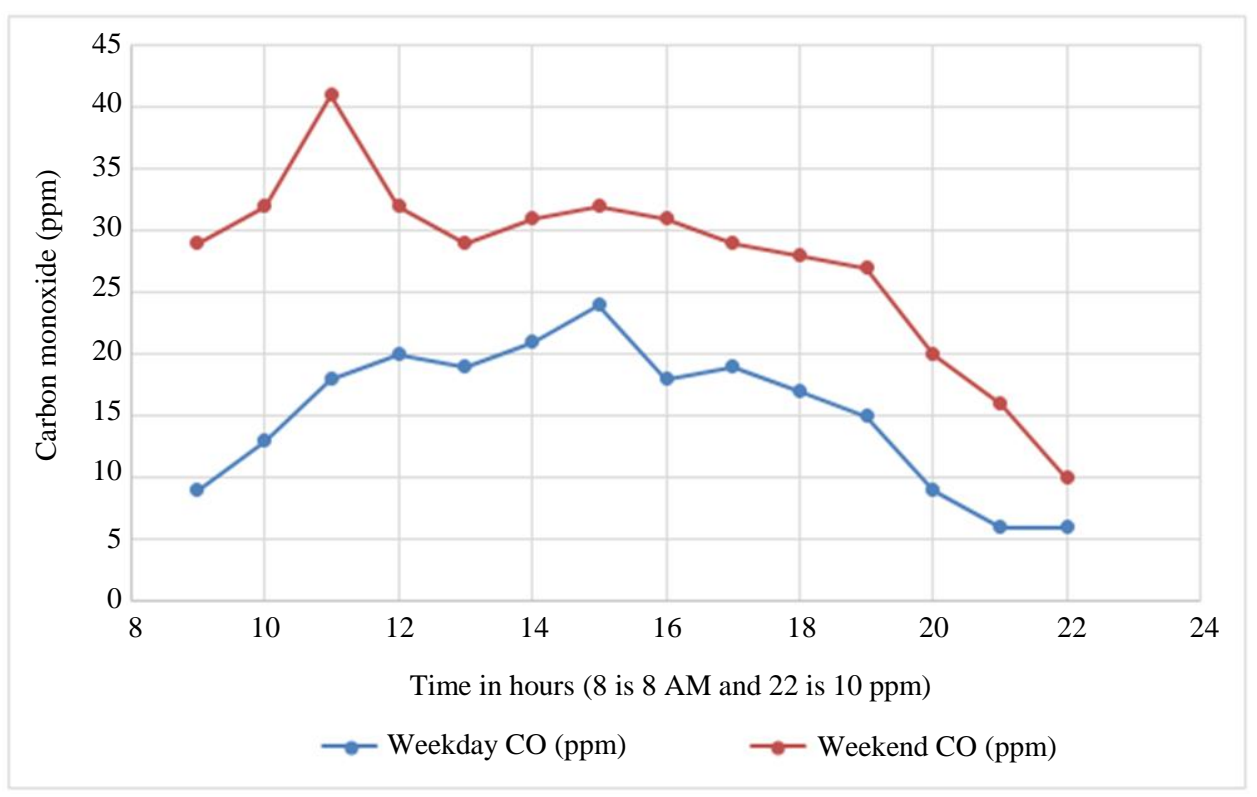

Fig. 7: CO concentration (ppm) averaged over $60 \mathrm{~min}$ in the Avenues open space Garage monitored during the Summer time

\section{Conclusion}

The analysis of the Mall's real mean ventilation was also shown to be significantly lower than those suggested by the Criterion of ASHRAE (e.g., $7.62 \mathrm{~L} / \mathrm{m}^{2}$ ). The real mean rate of ventilation is higher than normal. The estimated $\mathrm{CO}$ amount was contrasted to the actual average ventilation volume. As normal, there was no direct connection between the $\mathrm{CO}$ concentration and ventilation levels. The same refers to the limited data collected in the United States.

The following recommendations are made:

1) In order to keep the temperature and humidity in a comfortable level, the facilities for the parking attendant should be fitted with air conditioning units

2) In order to constantly track $\mathrm{CO}$ rates, $\mathrm{CO}$ sensors should be mounted inside the parking floors. If sensors recognize that $\mathrm{CO}$ levels are close to the standard I-hour (35 ppm), ventilation suppliers should automatically switch to double or triple speed in order to eliminate the build-up of the poisonous gas

3) The correct ventilation rate within the enclosed parking facility for the preservation of concentrations of $\mathrm{CO}$ contamination emissions at an acceptable level should be strictly monitored by the authorities

4) $\mathrm{CO}$ rates, particularly at night. The average $1 \mathrm{~h}$ astandard of 35 (ppm) was often surpassed for a short period of time. More experiments should be carried out regularly throughout the day (8:00 am to $12: 00 \mathrm{pm}$ ) for tracking $\mathrm{CO}$ rates in car parks. Such study is needed to determine the hourly and the $8 \mathrm{~h}$ concentration levels of $\mathrm{CO}$ and thus determine the exposure time for the parking attendants at enclosed garages
5) Actions should be taken by authorities concerning the installation of a catalytic converter (exhaust gas purifier) in vehicles. Catalytic converters reduce the output of Carbon Monoxide (CO), Hydrocarbons (HC) and oxides of Nitrogen (NOx) pollutants, by converting them into relatively harmless gases

\section{Acknowledgment}

The authors want to acknowledge the sincere and caring staff of the National Unit for Environmental Research and Services labs (NUERS) for their dedication and genuine help.

\section{Author's Contributions}

Nayef Z. Al-Mutairi: Writing the paper and analysis.

Talal Almutairi: Literature review, data collection and preparation.

Hamad B Matar: Editing and prepare for publication.

\section{Ethics}

This article is original and contains unpublished material. The corresponding author confirms that all of the other authors have read and approved the manuscript and no ethical issues involved.

\section{References}

Al-Mutairi, N., \& Koushki, P. (2009). Potential contribution of traffic to air pollution in the State of Kuwait. American Journal of Environmental Sciences, 5(3), 218. 
ASHRAE. (2007). ASHRAE Handbook: HVAC applications. American Society of Heating, Refrigerating and Air Conditioning Engineers.

Cacciola, R. R., Sarva, M., \& Polosa, R. (2002). Adverse respiratory effects and allergic susceptibility in relation to particulate air pollution: flirting with disaster. Allergy, 57(4), 281-286.

Calderón-Garcidueñas, L., Mora-Tiscareño, A., Fordham, L. A., Valencia-Salazar, G., Chung, C. J., Rodriguez-Alcaraz, A., ... \& Antunez-Solis, A. (2003). Respiratory damage in children exposed to urban pollution. Pediatric pulmonology, 36(2), 148-161.

Chan, M. Y., \& Chow, W. K. (2004). Car park ventilation system: performance evaluation. Building and Environment, 39(6), 635-643.

Chow, W. K., Wong, L. T., \& Fung, W. Y. (1996). Field study on the indoor thermal environment and carbon monoxide levels in a large underground car park. Tunnelling and underground space technology, 11(3), 333-343.

Demir, A. (2015). Investigation of air quality in the underground and aboveground multi-storey car parks in terms of exhaust emissions. Procedia-Social and Behavioral Sciences, 195, 2601-2611.

Dockery, D. W., Pope, C. A., Xu, X., Spengler, J. D., Ware, J. H., Fay, M. E., ... \& Speizer, F. E. (1993). An association between air pollution and mortality in six US cities. New England journal of medicine, 329(24), 1753-1759.
Höglund, P. G. (2004). Parking, energy consumption and air pollution. Science of the Total Environment, 334, $39-45$.

IARC. (2012). Diesel and gasoline engine exhaust and some nitroarenes. IARC Monographs on the Evaluation of Carcinogenic Risks to Humans, Lyon, France.

Kim, S. R., Dominici, F., \& Buckley, T. J. (2007). Concentrations of vehicle-related air pollutants in an urban parking garage. Environmental Research, 105(3), 291-299.

Koskela, H. K., Rolin, I. E., \& Norell, L. O. (1991). Comparison between forced-displacement and mixing ventilation in a garage. ASHRAE Transaction, 97, 1119-1126.

Vermeulen, R., Silverman, D. T., Garshick, E., Vlaanderen, J., Portengen, L., \& Steenland, K. (2014). Exposure-response estimates for diesel engine exhaust and lung cancer mortality based on data from three occupational cohorts. Environmental health perspectives, 122(2), 172-177.

Wallace, L. A. (1983). Carbon monoxide in air and breath of employees in an underground office. Journal of the Air Pollution Control Association, 33(7), 678-682.

Wilhelm, M., \& Ritz, B. (2003). Residential proximity to traffic and adverse birth outcomes in Los Angeles county, California, 1994-1996. Environmental health perspectives, 111(2), 207-216. 